\title{
Statyba
}

\section{THE CONTENT OF THE ACTIVE LAYER EXTERNAL SURFACE RESISTANCE TO WEATHERING}

\section{Barkauskas}

To cite this article: V. Barkauskas (2001) THE CONTENT OF THE ACTIVE LAYER EXTERNAL SURFACE RESISTANCE TO WEATHERING, Statyba, 7:1, 56-59, DOI: 10.1080/13921525.2001.10531699

To link to this article: https://doi.org/10.1080/13921525.2001.10531699

曲 Published online: 30 Jul 2012.

Submit your article to this journal $\pi$

III Article views: 41 


\section{AKTYVIOJO IŠORINIO PAVIRŠIAUS PATVARUMO APLINKOS POVEIKIAMS TURINYS (KIEKIS)}

\section{Barkauskas}

Architektūros ir statybos institutas

\section{Ivadas}

Žinoma, kad pastatų išorinio paviršiaus apdailą intensyviai veikia aplinkos salygos, ji sensta ir yra. Manoma, kad intensyviai veikiamas yra tokio storio apdailos sluoksnis, kuriame temperatūros ir paviršiaus igério kitimo amplitudès sumažeja (gęsta) perpus. Tarkime, kad sąlygiškai ši sluoksni galima pavadinti aktyviuoju paviršiaus sluoksniu. Šio sluoksnio, kaip ir bet kurios kitos mineralinès kilmès statybinès medžiagos, makrostruktūra nèra vienalytè - jos fizinių-mechaninių savybiụ sklaida ivertinama dispersija, variacijos koeficiento, vidutinio kvadratinio nuokrypio ir kitais statistiniais rodikliais.

Fizinių-mechaninių rodiklių sklaida būdinga ne tik atskiriems bandiniams ar imtims, bet taip pat ir kiekvieno bandinio mikrotūrių, turinčių tam tikrą fizinių-mechaninių savybių rinkinị, visumai. Suprantama, kad kiekvieno tokio mikrotūrio geba priešintis ịvairiems poveikiams yra nevienoda. Tą akivaizdžiai iliustruoja vienodai veikiamų, tačiau nevienodai senstančių ir yrančių išorinių paviršių lokalinių ploteliụ sklaida. Žinant aktyviojo paviršiaus tūri, jo mikrotūrių sklaidą, juose veikiančias jègas ir tam tikrą, statistiškai nustatytą mikrotūriụ gebą priešintis, galima ịvertinti ir viso paviršiaus apdailos senejjimo mąstą, pobūdị ir tempą. Kol kas literatūroje tokio vertinimo nepastebejome.

Statistiniai duomenys apie apdailos paviršiaus irimo ir senejjimo pobūdi, mūsų surinkti per daugelị natūrinių stebejjimų metų, taip pat vykdant specialius apdailu tyrimus klimatinèse kamerose, darant papildomus eksperimentus, analizuojant atitinkamą literatūrą, ypač joje naudotus šaltinius ir pirminę medžiagą, buvo apibendrinti statistiniais metodais, atmetant prieštaringas ar net klaidingas premisas. Išsamiai ištirtas akytbetonis ir keramika, kadangi jos senejjimo ir irimo procesus palyginti greitai galima pastebèti ir ivertinti.

\section{Aktyvusis atitvaru išorinio paviršiaus sluoksnis}

Vienalyčio aktyviojo sluoksnio storis $d_{a, \theta}$, kuriame temperatūrų amplitudè sumažèja perpus [1], apskaičiuojamas pagal formulę (1). Šioje transformuotoje formulèje pateikiama pataisa, priklausanti nuo temperatūru kitimo amplitudžių ant išorinio paviršiaus $\left(A_{s, \theta}\right)$ ir ore $\left(A_{e, \theta}\right)$ santykio [2]:

$$
d_{a, \theta}=0,399 \frac{A_{s, \theta}}{A_{e, \theta}} \sqrt{\frac{\lambda \cdot t}{c \cdot \rho}}, \mathrm{m},
$$

$\lambda$ - medžiagos šilumos laidumo koeficientas, $\mathrm{W} /(\mathrm{m} \cdot \mathrm{K})$; $t$ - laikas, h; $c$ - savitoji šiluminè talpa, $\mathrm{kJ} / \mathrm{kg} \cdot \mathrm{K}$; $\rho$ - tankis, $\mathrm{kg} / \mathrm{m}^{3}$.

Paviršinis vandens igèrio plitimo gylis sluoksnyje ivertinamas eksperimentu, nustatant paviršinio vandens gerties koeficientą $\omega$ [3]:

$$
\omega=\frac{\Delta W}{\Delta \sqrt{t}}, \mathrm{~kg} /\left(\mathrm{m}^{2} \cdot \mathrm{t}^{0.5}\right),
$$

$W$ - paviršinis sluoksnio vandens igẻris, $\mathrm{kg} / \mathrm{m}^{2}$.

Ryši tarp $W$ ir igèrio gylio $d_{a, u}$ galime išreikšti taip:

$$
d_{a, u}=W \cdot \frac{V}{m}, \mathrm{~m},
$$

$V$ - sluoksnio tūris, $\mathrm{m}^{3}$, tenkantis $1 \mathrm{~kg}$ vandens masès $\boldsymbol{m}$.

Yra žinoma, kad vienalytès medžiagos paviršiaus ilgaamžiškumas $T_{a}$ yra proporcingas jo storio kvadratui ir to sluoksnio patvarumo bei poveikių komplekso santykiui $[4,5]$ :

$$
T_{a}=\frac{G}{K_{1} \cdot K_{2} \cdot \ldots \cdot K_{n}} d_{a}^{2}, \mathrm{~m} \text { (ciklai), }
$$

$G$ - sluoksnio geba (patvarumas) priešintis ardančiai poveikiụ energijai; $K_{1} \cdot K_{2} \cdot \ldots \cdot K_{n}$ - funkciniai dalikliai, apibūdinantys poveikių energija, jos krypti, prigimtị ir pan. 
Kiekvienas funkcinis daliklis yra kompleksinio kintamojo funkcija ir todèl atitinkamų tyrimų ir mokslinès analizès objektas, išreiškiamas jam būdingomis vertèmis ir dimensijomis.

\section{Aktyviojo sluoksnio vidinès energijos sankaupa (turinys, kiekis)}

Šiame straipsnyje nagrinejjame tik tuos poveikius, kurie medžiagos skeleto sienelèse sukelia tempimo ittempimus ir medžiagos sieneliụ atsparumo tempiant mažèjimą.

Mūsų atlikti akytbetonio ir keramikos ilgaamžiškumo tyrimai leidžia teigti, kad bandinių sąlyginiụ mikrotūrių, kuriems būdingos tam tikros fizinès-mechaninès savybès, sklaida yra pakankamai asimetriné ir turi kairiji nuokrypi. Šis nuokrypis yra esminis veiksnys išorinio paviršiaus akytojo sluoksnio senèjimo ir irimo procesuose.

Statistiškai ivertinę ir sutvarkę duomenis, nustatème, kad ịvairaus patvarumo mikrotūriụ sklaida gali būti ivertinta Maksvelio kreivèmis [5, 6]:

$$
\Phi(\bar{X}-\beta)=\sqrt{\frac{2}{\pi}} \frac{(\bar{X}-\beta)^{2}}{\alpha^{3}} e^{-\frac{(\bar{X}-\beta)^{2}}{2 \alpha^{2}}},
$$

o kreivèmis apibrèžiamas plotas $A$ :

$$
A=\sqrt{2 \pi} \int_{R_{\min }}^{R_{\max }}(\bar{X}-\beta)^{2} e^{-\frac{(\bar{X}-\beta)^{2}}{2}} d(\bar{X}-\beta),
$$

$\bar{X}$ - vidutinis stipris tempimui, MPa; $\alpha-$ savybiu sklaidos parametras, $\alpha=\frac{\sigma}{\sqrt{3-\frac{8}{\pi}}}=\frac{\sigma}{0,627} ; \beta$ - asimetrijos rodiklis. Remiantis empiriniais duomenims, $\beta=\bar{X}-\frac{\sigma}{0,422}, \sigma-$ kvadratinis nuokrypis, MPa.

Tardami, kad paveiksle a nurodyta kreivè perstumta $\mathrm{Z}$ ašies kryptimi per ilgio vieneta, ir integruodami 6 lygti, gauname atitinkamą gaminio (aktyviojo sluoksnio) tưri $V=A \cdot d_{a}, \mathrm{~m}^{3}$, kai parametro $\mathrm{z}$ riba yra vienetas.

$$
V=z \int_{X_{\min }}^{X_{\max }} \varphi(\bar{X}-\beta) d(\bar{X}-\beta)=\Phi[\bar{X}-\beta] .
$$

Integruota šiame tūryje vidinè energija $\mu$ (atsparumo kiekis, turinys) yra:

$$
\mu=G=V \cdot \bar{X}, \mathrm{Nm} .
$$

Tai reiškia gaminio (paviršiaus aktyviojo sluoksnio) vidinès energijos sankaupą džauliais, kuriai suma-
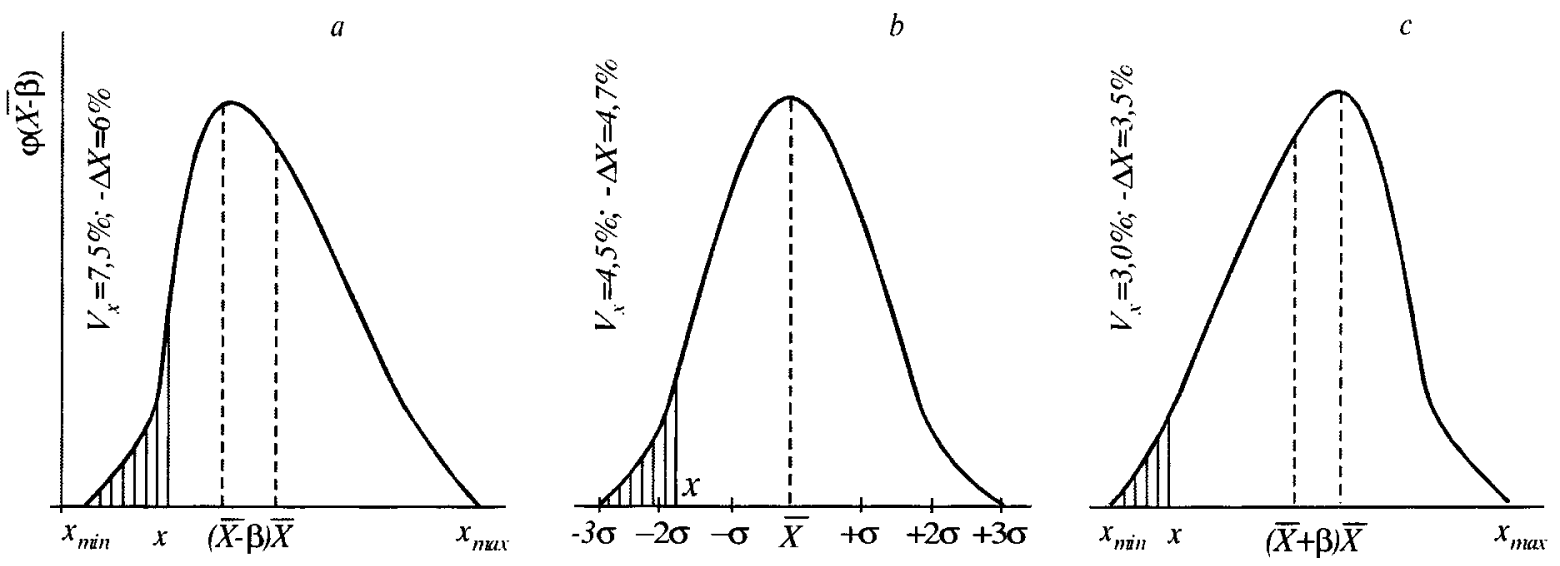

Parametro $x$ (stiprio tempimui) sklaidos skale

Statistiškai apibendrintos silikatbetonio ir keramikos gaminių stiprio tempimui sklaidos kreivès: a - pagal Maksvelio dèsni, b palyginimui - to paties ploto simetrinè kreivè, c palyginimui - to paties ploto kreivè, turinti dešiniji nuokrypi

Distribution curves for tension: according to Maxwell law, b - for comparison, symmetric curve of the same area, c for comparison, curve of the same area in the right kurtosis 
žinti ar sunaikinti reikia atitinkamo išorinès energijos kiekio (darbo). Senejjimas ir irimas gali būti ivertintas laiko funkcija $T_{x}$ [4]:

$$
T_{x}=\varphi\left[\Phi_{T_{1}}^{T_{2}}(\bar{X}-\beta)\right], \mathbf{m} \text { (ciklai) }
$$

t. y. laiku, per kuri bus suardyta tam tikra tūrio dalis $d V_{a} / V$, atitinkamai sumažindama vidinès energijos $\mu$ sankaupą, neskaitant, kad kai kurie mikrotūriai bus cikliškai varginami jègomis, artimomis kritiškoms. Tariant, kad kritiškojo poveikio riba yra dydis $a$, likutinès vidinès energijos $\mu_{T}$ (likutinès gebos priešintis poveikiams) sankaupa gali būti apytikriai ịvertinta santykiu:

$$
\mu=a \cdot \bar{X}=\frac{\left(\bar{X} V-X_{a} V_{a}\right)}{\bar{X}}, \mathrm{~kg} \cdot \mathrm{m}
$$

Taigi (7) lygti tenka integruoti intervalu nuo $x_{\min }$ iki $x_{a}$. Vengiant nuolat integruoti (7) lygti, pateikiame integralo $\bar{\Phi}(x)=\sqrt{\frac{2}{\pi}} \int_{0}^{x} x^{2} e^{-\frac{1}{2} x^{2}} d x$ reikšmes (žr. lentelę).

\section{Taikomoji reikšmė}

Turint statistines kai kurių medžiagụ fizinių-mechaninių savybių sklaidos kreives, šios analizès taikomoji reikšmė yra ta, kad galima tenkinti (4) formulę, jeigu pagrindiniai poveikiai yra temperatūrų kaita ir medžiagos drègnis.

Užšąlančio vandens hidrostatinis slègis $p$ ivertinamas kvadratine lygtimi [7]:

$$
A p^{2}+B p-C=0
$$

$p$ - užšąlančio vandens hidrostatinis slègis, $\mathrm{Pa} ; A, B$ ir $C$ - lygties parametrai:

$$
\begin{gathered}
A=\frac{1-2 \mu}{E} \cdot \frac{p_{0}}{1-p_{0}} \cdot \\
{\left[1+\frac{1+\mu}{2(1-2 \mu) p_{0}}+\frac{1-2 \mu}{E}(1+3 \eta) \frac{\Psi}{p_{0}}\right],} \\
B=A+\frac{1}{3}-\frac{1+3 \eta}{3} \cdot \frac{\Psi}{p_{0}}, \\
C=\eta \frac{\Psi}{p_{0}},
\end{gathered}
$$

$E$ - medžiagos tamprumo modulis, $\mathrm{Pa} ; \mu$ - Puasono

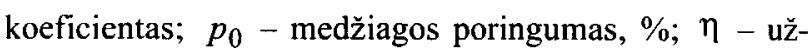
šąlančio vandens išsiplètimo koeficientas, $\% ; \Psi-$ tūrinis medžiagos drègnis, \%.

Santykinio tūrio vertés priklausomai nuo kintamojo $x=\frac{\bar{X}-\beta}{\alpha}$ integruojant funkciją $\bar{\Phi}(x)$

Values of relative volume depending on the variable $x=\frac{\bar{X}-\beta}{\alpha}$ when integrating function $\bar{\Phi}(x)$

\begin{tabular}{|c|c|c|c|c|c|c|c|}
\hline$x$ & $\bar{\Phi}(x)$ & $x$ & $\bar{\Phi}(x)$ & $x$ & $\bar{\Phi}(x)$ & $x$ & $\bar{\Phi}(x)$ \\
\hline 0,05 & 0,0002 & 1,05 & 0,2225 & 2,05 & 0,7583 & 3,05 & 0,9750 \\
\hline 0,15 & 0,0012 & 1,15 & 0,2745 & 2,15 & 0,7973 & 3,15 & 0,9830 \\
\hline 0,25 & 0,004 & 1,25 & 0,3297 & 2,25 & 0,8320 & 3,25 & 0,9866 \\
\hline 0,35 & 0,0110 & 1,35 & 0,3872 & 2,35 & 0,8624 & 3,35 & 0,9906 \\
\hline 0,45 & 0,0220 & 1,45 & 0,4457 & 2,45 & 0,8868 & 3,45 & 0,9937 \\
\hline 0,55 & 0,0400 & 1,55 & 0,5042 & 2,55 & 0,9102 & 3,55 & 0,9961 \\
\hline 0,65 & 0,0640 & 1,65 & 0,5614 & 2,65 & 0,9288 & 3,65 & 0,9978 \\
\hline 0,75 & 0,0950 & 1,75 & 0,6154 & 2,75 & 0,9442 & 3,75 & 0,9989 \\
\hline 0,85 & 0,1320 & 1,85 & 0,6675 & 2,85 & 0,9565 & 3,85 & 0,9996 \\
\hline 0,95 & 0,1745 & 1,95 & 0,7150 & 2,95 & 0,9667 & 3,95 & 0,9999 \\
\hline 1,00 & 0,1975 & 2,00 & 0,7276 & 3,00 & 0,9712 & 4,00 & 0,9999 \\
\hline
\end{tabular}


Kritinis medžiagos stipris tempimui gali būti ịvertintas formule $[4,6,7]$ :

$$
\sigma_{k r}=a k \sqrt[3]{\left(\frac{R}{p_{0}}\right)^{2}}, \mathrm{~Pa}
$$

$a$ - medžiagos masès charakteristika, vieneto dalimis; $k$ - suminkštèjimo koeficientas; $R$ - stipris gniuždymui, Pa.

\section{Išvados}

1. Atitvarų išorinio paviršiaus senejjimo ir irimo procesai iš esmès vyksta šio paviršiaus aktyviajame, turinčiame tam tikrą stori ir tūri sluoksnyje, ir tik tuo aspektu nagrinètini.

2. Visuminè (integraliné) šio sluoksnio atsparumo poveikiams geba yra baigtinis dydis, kuri galima ịvertinti ir ivardyti kaip atsparumo kieki (turinị) arba vidinès energijos sankaupa.

3. Pagal statistines kreives galima apskaičiuoti vidinès energijos mažėjimą senstant ir yrant atskiriems aktyviojo sluoksnio mikrotūriams, veikiant juardytiems ir atitinkamai ivertintiems išoriniams poveikiams, ir numatyti laiką, per kuri aktyvusis sluoksnis susilpnès iki numatyto lygmens.

\section{Literatūra}

1. К. Фокин. Строительная теплотехника ограждающих частей зданий. М.: Стройиздат, 1973. 118 с.

2. Kurt Weinman, Günter Reiche. Handbuch Bautenschute, Band 1, Bauphysik, Expert Verlag, 1990, S. 191.

3. DIN 52617. Bestinmung des Wasseraufnahmekoeffizienten von Baustoffen, 1987.

4. В. М. Ильинский. Проектирование ограждающих конструкций зданий с учетом физико-климатических воздействий. Дис. ... д-ра техн. наук. М.: МИСИ. 1965.
5. В. Баркаускас. Влияние влажного климата на долговечность лицевого слоя наружных стен. Дис. ... д-ра техн. наук. М.: МИСИ. 1962.

6. V. Barkauskas. Statybinių medžiagu fizinių-mechaniniu savybių sklaida - jų ilgaamžiškumo matas // ASI mokslo darbai. Kaunas, 1999. 73 p.

7. С. Власов, Г. Еремеев. Некоторые вопросы долговечности ограждающих конструкций // Известия $\mathrm{AC}$ и $\mathrm{A}$ CCCP, № 3, 1959.

Iteikta 20000628

THE CONTENT OF THE ACTIVE LAYER EXTERNAL SURFACE RESISTANCE TO WEATHERING

\section{Barkauskas}

\section{Summary}

The external surfaces of finish wear and disintegrate under weathering conditions. It is known that the layer in which the amplitude of temperature and surface moisture decreases twice is intensively affected. When investigating the surface durability, it would be useful to call this layer an active layer. Its durability is proportional to the square of the layer thickness and to the ratio of inner energy (meant for resistantial influence).

Usually the dispersion of physical and mechanical properties in materials and samples is calculated by statistic methods. Analytically it is possible to assume that any product or sample consists of many hypothetic microvolumes demonstrating certain physical and mechanical properties. According to our tests carried out during years, the dispersion of these microvolumes is similar to that of products or samples and may be estimated by statistic curves.

Vytautas BARKAUSKAS. Doctor. Merited Architect of Lithuania. Senior Researcher. Institute of Architecture and Construction, ASI, Tunelio g. 60, LT-3035 Kaunas, Lithuania. A graduate of Kaunas Polytechnic Institute (1953) and Moscow Civil Engineering Institute (MISI, 1962).

Author and co-author of 3 monographs, 2 study guides and over 40 scientific articles. Designer of several residences and many renovated buildings. Author of architectural acoustic design for a number of public buildings. Research interests: influence of industry on architecture, durability of protective and decorative finish, building thermal physics. 